\title{
A Human PBPK/PD Model to Assess Arsenic Exposure Risk Through Farmed Tilapia Consumption
}

\author{
M.-P. Ling · C.-M. Liao
}

Received: 20 November 2008/ Accepted: 30 April 2009/Published online: 19 May 2009

(C) Springer Science+Business Media, LLC 2009

\begin{abstract}
The purpose of this study was to develop a biologically based risk assessment model for human health through consumption of arsenic (As) contaminated farmed tilapia (Oreochromis mossambicus) from blackfoot disease (BFD)-endemic area in Taiwan for estimating the consumption advice. We linked a physiologically based pharmacokinetic (PBPK) and a pharmacodynamic (PD) model to account for the exposure and dose-response profiles of As in human. Risk analysis indicates that consumption of farmed tilapia poses no significant threat from As-induced lung and bladder cancers. The predicted riskbased median consumption advice was no more than 5-17 meals month ${ }^{-1}$ (or 2-6 $\mathrm{g} \mathrm{day}^{-1}$ ).
\end{abstract}

Keywords Arsenic · PBPK/PD - Risk analysis · Consumption advice

Arsenic (As) is a common environmental toxicant and a known human carcinogen. Tseng et al. (2007) indicated that long-time exposure to ingest inorganic As in groundwater has been found to induce blackfoot disease (BFD). BFD is a unique peripheral vascular disease that ends with dry gangrene and spontaneous amputation of affected extremities in a limited area on the southwest coast of

M.-P. Ling $(\bowtie)$

Department of Health Risk Management, China

Medical University, Taichung 40402, Taiwan,

ROC

e-mail: lingmp@mail.cmu.edu.tw

C.-M. Liao

Department of Bioenvironmental Systems Engineering,

National Taiwan University, Taipei 10617, Taiwan, ROC
Taiwan. Nowadays, most of the people living in these areas do not drink groundwater. However, groundwater is still used for aquaculture. Farming of tilapia (Orechromis mossambicus) is a promising business at BFD-endemic area in Taiwan. Agency for Toxic Substances and Disease Registry (ATSDR) (2000) indicated that ingestion of As may increase the risks of internal cancers. ATSDR (2000) further noted the occurrence of internal tumors of the internal tissues in patients with As-induced skin cancer. However, the USEPA has not yet calculated a specific risk value or cancer slope factor for As-induced internal cancers (ATSDR 2000). In this study, we developed a risk model that linked a physiologically based pharmacokinetic (PBPK) model and a pharmacodynamic (PD) model. The PBPK model can estimate As exposure distributions in human blood, lung, bladder, skin, and GI tract. The PD model can be used to reconstruct dose-response functions for arsenicosis (hyperpigmentation and keratosis) and Asinduced cancers (lung, bladder, and skin cancers). We combined the exposure distribution profiles and the reconstructed dose-response profiles to predict and to compare the human As exposure risks for subsistence fishers in BFD-endemic area and residents in non-BFDendemic area in Taiwan region.

The purposes of this study were: (1) to conduct an biologically-based risk assessment based on the USEPA (1998) methodology for human As exposure risk through consumption of farmed tilapia from BFD-endemic area in Taiwan; (2) to address the uncertainties by using a probabilistic PBPK/PD approach to characterize risks that yield quantitative risk estimates and their associated uncertainties; and (3) to estimate risk-based consumption advice regarding As contaminated farmed tilapia based on USEPA (2000) approach for potential carcinogenic risks. 


\section{Materials and Methods}

The pathway of As exposure for human is through farmed tilapia consumption. Farmed tilapia is contaminated with organ $i,\{u(t)\}$ represents an input vector of chemical concentration in tilapia muscle, $[K]$ is a state matrix describes the diffusion exchange rate between target organs,

$$
[K]=\left[\begin{array}{ccccc}
-\left(Q_{\mathrm{L}}+Q_{\mathrm{BL}}+Q_{\mathrm{S}}+Q_{\mathrm{GI}}\right) \frac{F_{\mathrm{D}}}{V_{\mathrm{B}}} & \frac{Q_{\mathrm{L}}}{R_{\mathrm{L}} V_{\mathrm{B}}} & \frac{Q_{\mathrm{BL}}}{R_{\mathrm{BL}} V_{\mathrm{B}}} & \frac{Q_{\mathrm{S}}}{R_{\mathrm{S}} V_{\mathrm{B}}} & \frac{Q_{\mathrm{GI}}}{R_{\mathrm{GI}} V_{\mathrm{B}}} \\
\frac{Q_{\mathrm{L}} F_{\mathrm{D}}}{W_{\mathrm{L}}} & -\left(\frac{Q_{\mathrm{L}}}{R_{\mathrm{L}} W_{\mathrm{L}}}\right) & 0 & 0 & 0 \\
\frac{Q_{\mathrm{BL}} F_{\mathrm{D}}}{W_{\mathrm{BL}}} & 0 & -\left(\frac{Q_{\mathrm{BL}}}{R_{\mathrm{BL}} W_{\mathrm{BL}}}+K_{\mathrm{U}}\right) & 0 & 0 \\
\frac{Q_{\mathrm{S}} F_{\mathrm{D}}}{W_{\mathrm{S}}} & 0 & 0 & -\left(\frac{Q_{\mathrm{S}}}{R_{\mathrm{S}} W_{\mathrm{S}}}\right) & 0 \\
\frac{Q_{\mathrm{GI}} F_{\mathrm{D}}}{W_{\mathrm{GI}}} & 0 & 0 & 0 & -\left(\frac{Q_{\mathrm{GI}}}{R_{\mathrm{GI}} W_{\mathrm{GI}}}+K_{\mathrm{F}}\right)
\end{array}\right],
$$

As through groundwater. Exposures of subsistence fishers in BFD-endemic area and residents in non-BFD-endemic area to As were only through consumption of farmed tilapia obtained from tilapia farms in BFD-endemic area. We assumed people only eating the muscle part of contaminated farmed tilapia. The As level in farmed tilapia muscle is determined by using a physiologically based toxicokinetic (PBTK) model (Ling et al. 2005). In this and $[X]$ is a constant input matrix describes the exchange rate into the target organ,

$[X]=\left[\begin{array}{lllll}0 & 0 & 0 & 0 & \frac{C R \alpha}{W_{\mathrm{GI}}}\end{array}\right]^{\mathrm{T}}$.

We considered the steady-state condition in Eq. 1 and respectively solved for the steady-state As concentrations in human lung $\left(C_{\mathrm{L}}\right)$, bladder $\left(C_{\mathrm{BL}}\right)$, and skin $\left(C_{\mathrm{S}}\right)$,

$$
\begin{aligned}
& C_{\mathrm{L}}=\frac{Q_{\mathrm{L}} F_{\mathrm{D}} I J C G}{\left[A F H I J-\left(H I J B Q_{\mathrm{L}} F_{\mathrm{D}}+F I J C Q_{\mathrm{BL}} F_{\mathrm{D}}+F H J D Q_{\mathrm{S}} F_{\mathrm{D}}+F H I E Q_{\mathrm{GI}} F_{\mathrm{D}}\right)\right]}, \\
& C_{\mathrm{BL}}=\frac{Q_{\mathrm{BL}} F_{\mathrm{D}} F I C G}{\left[A F H I J-\left(H I J B Q_{\mathrm{L}} F_{\mathrm{D}}+F I J C Q_{\mathrm{BL}} F_{\mathrm{D}}+F H J D Q_{\mathrm{S}} F_{\mathrm{D}}+F H I E Q_{\mathrm{GI}} F_{\mathrm{D}}\right)\right]}, \\
& C_{\mathrm{S}}=\frac{Q_{\mathrm{S}} F_{\mathrm{D}} F J C G}{\left[A F H I J-\left(H I J B Q_{\mathrm{L}} F_{\mathrm{D}}+F I J C Q_{\mathrm{BL}} F_{\mathrm{D}}+F H J D Q_{\mathrm{S}} F_{\mathrm{D}}+F H I E Q_{\mathrm{GI}} F_{\mathrm{D}}\right)\right]},
\end{aligned}
$$

study, the inorganic As level is account for $7.4 \%$ of the total As in farmed tilapia from BFD-endemic area (Huang et al. 2003).

We used a PBPK model to simulate inorganic As accumulation in human target organs through farmed tilapia muscle consumption. Our PBPK model structure consists of lung (compartment 2), bladder (compartment 3 ), skin (compartment 4), and GI tract (compartment 5), which were interconnected by blood (compartment 1) circulation. The present PBPK models can be described by a linear dynamic equation (Yu 1998, 1999a, b),

$\frac{d\left\{C_{\mathrm{H}, \mathrm{i}}(t)\right\}}{d t}=[K]\left\{C_{\mathrm{H}, \mathrm{i}}(t)\right\}+[X]\{u(t)\}$,

where $\left\{C_{\mathrm{H}, \mathrm{i}}(t)\right\}$ is a state variable vector which describes the chemical concentration in each assigned human target where $A=F_{\mathrm{D}}\left(Q_{\mathrm{L}}+Q_{\mathrm{BL}}+Q_{\mathrm{S}}+Q_{\mathrm{GI}}\right), \quad B=Q_{\mathrm{L}} R_{\mathrm{L}}^{-1}, \quad C=$ $Q_{\mathrm{BL}} R_{\mathrm{BL}}^{-1}, \quad D=Q_{\mathrm{S}} R_{\mathrm{S}}^{-1}, E=Q_{\mathrm{GI}} R_{\mathrm{GI}}^{-1}, F=Q_{\mathrm{L}} R_{\mathrm{L}}^{-1}+K_{\mathrm{H}}$ $W_{\mathrm{L}}, \quad G=C R \alpha C_{\mathrm{F}, \mathrm{m}}, \quad H=Q_{\mathrm{GI}} R_{\mathrm{GI}}^{-1}+C R \alpha K_{\mathrm{F}} T, \quad I=Q_{\mathrm{S}}$ $R_{\mathrm{S}}^{-1}+K_{\mathrm{S}} B W$, and $J=Q_{\mathrm{BL}} R_{\mathrm{BL}}^{-1}+K_{\mathrm{U}} W_{\mathrm{BL}}$, in that $C_{\mathrm{F}, \mathrm{m}}$ is the As concentration in tilapia muscle $\left(\mu \mathrm{g} \mathrm{g}^{-1}\right) ; Q_{\mathrm{i}}$ is the diffusive exchange rate of organ $i\left(\mathrm{~L} \mathrm{day}^{-1}\right) ; F_{\mathrm{D}}$ is the binding coefficient of As concentration to plasma proteins ( $\left.\mathrm{g} \mathrm{L}^{-1}\right) ; R_{\mathrm{i}}$ defines as $C_{\mathrm{i}} / C_{\mathrm{di}}$, which denotes the partition coefficient or is referred to as an organ/blood equilibrium distribution ratio for linear binding in specific organ $i$ $\left(\mathrm{L} \mathrm{g}^{-1}\right)$ in that $C_{\mathrm{i}}$ is the total As concentration in human target organ $i\left(\mu \mathrm{g} \mathrm{g}^{-1}\right)$ and $C_{\mathrm{di}}$ is the dissolved As concentration in the blood leaving target organ $i$ $\left(\mu \mathrm{g} \mathrm{mL}^{-1}\right) ; V_{\mathrm{B}}$ is the blood volume (L); $C R$ is the daily tilapia muscle consumption rate $\left(\mathrm{g}^{\text {day }}{ }^{-1}\right) ; W_{\mathrm{L}}, W_{\mathrm{BL}}$ and $W_{\mathrm{GI}}$ are the organ weight of lung, bladder and GI tract $(\mathrm{g})$, 
respectively; $B W$ is the consumer body weight $(\mathrm{kg}) ; \alpha$ is absorption efficiency of As (\%); $T$ is time to $95 \%$ steady state in GI tract (days); $K_{\mathrm{H}}$ is the respiration rate $\left(\mathrm{g} \mathrm{g}^{-1}\right.$ day $\left.{ }^{-1}\right)$; $K_{\mathrm{U}}$ is the urine elimination rate $\left(\mathrm{g} \mathrm{g}^{-1}\right.$ day $\left.^{-1}\right) ; K_{\mathrm{S}}$ is the sweat elimination rate $\left(\mathrm{g} \mathrm{g}^{-1} \mathrm{day}^{-1}\right)$ and $K_{\mathrm{F}}$ is the fecal elimination rate $\left(\mathrm{g} \mathrm{g}^{-1} \mathrm{day}^{-1}\right)$. The respiration rate and sweat elimination rate are much less than the elimination rate in bladder and GI tract. Hence, we ignored the respiration rate and sweat elimination rate (Table 1).

Dose-response functions for morbidity and fatality effects versus As level in target human organs were fitted by using a empirical three-parameter Hill equation based PD model to the previously published dose-response functions of the quadratic-exponential for arsenicosis and
As-induced cancers based on epidemiological data from West Bengal and Taiwan (Yu et al. 2003). The reconstructed dose-response profiles for given organ-specific As concentration in human, $P\left(E_{\mathrm{i}} \mid C_{\mathrm{H}, \mathrm{i}}\right)$ could be expressed as conditional cumulative distribution function (cdf),

$P\left(E_{\mathrm{i}} \mid C_{\mathrm{H}, \mathrm{i}}\right)=\Phi\left(\frac{E_{\max } \times C_{\mathrm{H}, \mathrm{i}}^{n}}{E C_{50, \mathrm{i}}^{n}+C_{\mathrm{H}, \mathrm{i}}^{n}}\right)$,

where $C_{\mathrm{H}, \mathrm{i}}$ is the internal As concentration in human target organ $i\left(\mu \mathrm{g} \mathrm{g}^{-1}\right), E_{\mathrm{i}}$ is human prevalence or incidence of those exposed to As through farmed tilapia consumption, $E_{\max }$ is human maximum prevalence or incidence that assumed values were $100 \%, \mathrm{EC}_{50, \mathrm{i}}$ is the $50 \%$ effect

Table 1 Input parameters values for human used for PBPK model simulation

\begin{tabular}{|c|c|c|}
\hline Parameters & Symbol & Value \\
\hline \multicolumn{3}{|l|}{ Physiological parameters for human } \\
\hline \multicolumn{3}{|l|}{ Blood perfusion rate $\left(\mathrm{L} \mathrm{day}^{-1}\right)^{\mathrm{a}}$} \\
\hline Lung & $Q_{\mathrm{L}}$ & 230.4 \\
\hline Bladder & $Q_{\mathrm{BL}}$ & 1,368 \\
\hline Skin & $Q_{\mathrm{S}}$ & 504.0 \\
\hline GI tract & $Q_{\mathrm{GI}}$ & $1,382.4$ \\
\hline \multicolumn{3}{|l|}{ Partition coefficient $\left(\mathrm{L} \mathrm{g}^{-1}\right)^{\mathrm{b}}$} \\
\hline Lung:blood & $R_{\mathrm{L}}$ & 4.15 \\
\hline Bladder:blood & $R_{\mathrm{BL}}$ & 4.15 \\
\hline Skin:blood & $R_{\mathrm{S}}$ & 2.5 \\
\hline GI tract:blood & $R_{\mathrm{GI}}$ & 2.5 \\
\hline Fraction As dissolved in blood $\left(\mathrm{g} \mathrm{L}^{-1}\right)^{\mathrm{c}}$ & $F_{D}$ & 0.2 \\
\hline Time to $95 \%$ steady state in GI tract (days) ${ }^{\mathrm{d}}$ & $T$ & 1 \\
\hline Absorption efficiency of As $(\%)^{\mathrm{e}}$ & $\alpha$ & 35 \\
\hline Body weight $(\mathrm{kg})$ & $B W$ & $\mathrm{~N}(60.55,4.67)^{\mathrm{f}}$ \\
\hline Bladder weight $(\mathrm{g})$ & $W_{\mathrm{BL}}$ & $\mathrm{N}(268.78,26.88)^{\mathrm{g}}$ \\
\hline \multicolumn{3}{|l|}{ Daily tilapia consumption rate $\left(\mathrm{g} \mathrm{day}^{-1}\right)$} \\
\hline Subsistence fishers $\left(2-6\right.$ meals week $\left.{ }^{-1}\right)$ in BFD-endemic area ${ }^{\mathrm{h}}$ & $C R_{2-6}$ & $\mathrm{LN}(22.07,2.61)$ \\
\hline Subsistence fishers (7-14 meals week $\left.{ }^{-1}\right)$ in BFD-endemic area ${ }^{\mathrm{h}}$ & $C R_{7-14}$ & $\mathrm{LN}(36.68,1.75)$ \\
\hline Residents (average tilapia consumption rates) in Taiwan ${ }^{\mathrm{i}}$ & $C R_{\text {average }}$ & $\mathrm{LN}(10.26,1.10)$ \\
\hline Meal size for human eating tilapia $\left(\mathrm{g} \mathrm{meal}^{-1}\right)^{\mathrm{j}}$ & $M S$ & $\mathrm{LN}(10.26,1.10)$ \\
\hline \multicolumn{3}{|l|}{ Biokinetic parameters ${ }^{\mathrm{k}}$} \\
\hline Urine elimination rate $\left(\right.$ day $\left.^{-1}\right)$ & $K_{\mathrm{U}}$ & $\mathrm{LN}(1.79,1.10)$ \\
\hline Fecal 64elimination rate $\left(\mathrm{day}^{-1}\right)$ & $K_{\mathrm{F}}$ & $\mathrm{LN}(0.029,1.11)$ \\
\hline \multicolumn{3}{|l|}{ Chemical parameter $^{1}$} \\
\hline As concentration in tilapia muscle $\left(\mu \mathrm{g} \mathrm{g}^{-1}\right)$ & $C_{\mathrm{F}, \mathrm{m}}$ & $\mathrm{LN}(0.52,2.60)$ \\
\hline \multicolumn{3}{|l|}{ Dose-response parameters } \\
\hline \multicolumn{3}{|l|}{ Median effective concentration $\left(\mu \mathrm{g} \mathrm{g}^{-1}\right)^{\mathrm{m}}$} \\
\hline Hyperpigmentation & $E C_{50, \text { Hyper }}$ & $\mathrm{N}(4.593,1.197)$ \\
\hline Keratosis & $E C_{50, \mathrm{Ker}}$ & $\mathrm{N}(6.360,0.883)$ \\
\hline Skin cancer & $E C_{50, \mathrm{SC}}$ & $\mathrm{N}(4.647,0.361)$ \\
\hline Lung cancer & $E C_{50, \mathrm{LC}}$ & $\mathrm{N}(222.0,56.569)$ \\
\hline Bladder cancer & $E C_{50, \mathrm{BC}}$ & $\mathrm{N}(470.0,31.113)$ \\
\hline
\end{tabular}


Table 1 continued

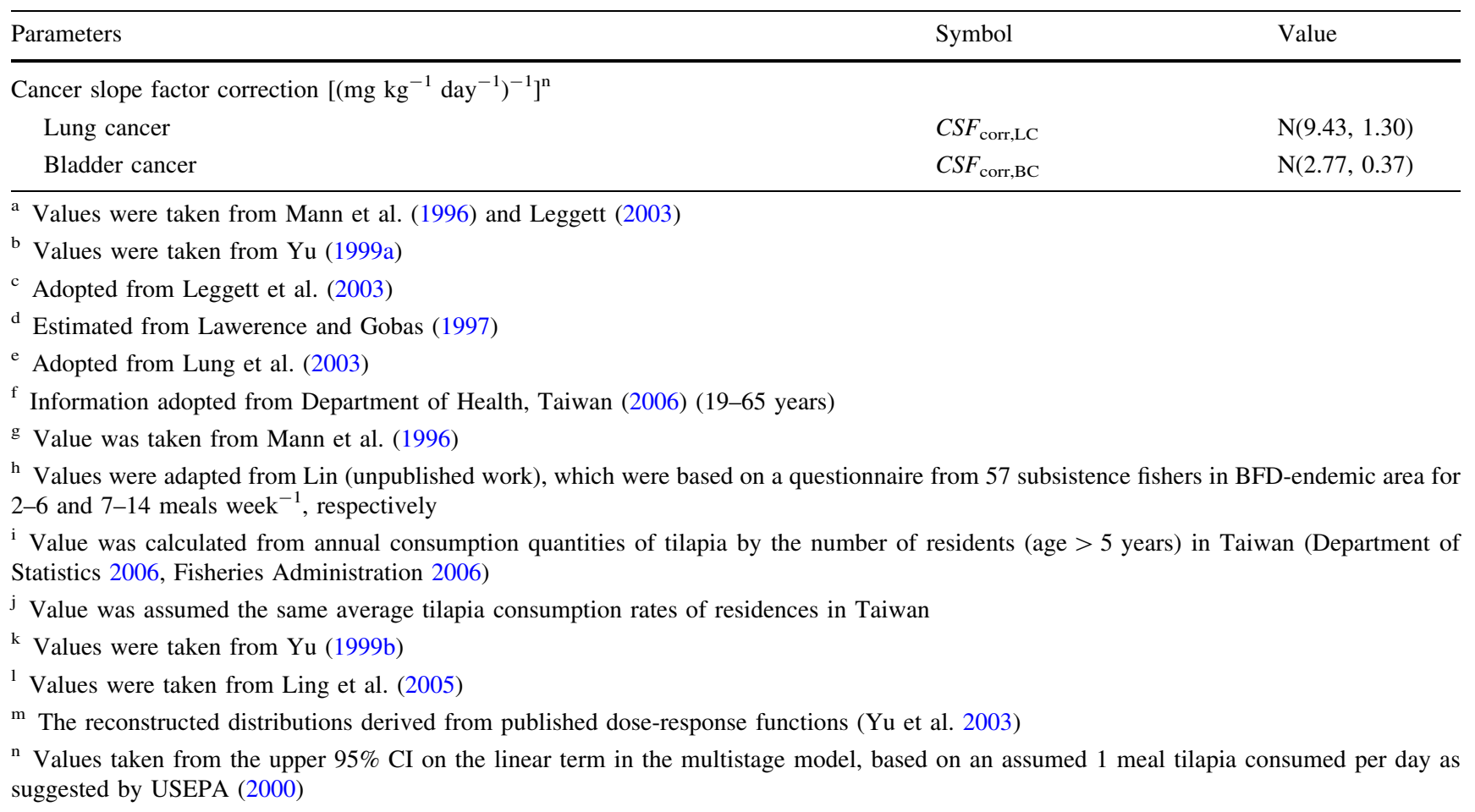

concentration $\left(\mu \mathrm{g} \mathrm{g}^{-1}\right)$ of the $E_{\max }, n$ is the Hill coefficient which is a measure of cooperativity, and $\Phi(\bullet)$ is the cumulative standard normal distribution.

Risk at a specific As concentration in human target organ in a joint probability function or exceedence profile, which describes the probability of exceeding the concentration associated with a particular degree of effect. This can be expressed mathematically as

$P\left(R_{C_{\mathrm{H}, \mathrm{i}}}\right)=P\left(C_{\mathrm{H}, \mathrm{i}}\right) P\left(E_{\mathrm{i}} \mid C_{\mathrm{H}, \mathrm{i}}\right)$,

where $P\left(R_{\mathrm{C}_{\mathrm{H}, \mathrm{i}}}\right)$ is the risk for a specific organ $i$ at concentration $C_{\mathrm{H}, \mathrm{i}}$, and $P\left(C_{\mathrm{H}, \mathrm{i}}\right)$ is the cdf of having organ concentration $C_{\mathrm{H}, \mathrm{i}}$.

We predicted the consumption advice for As based on estimates of potential carcinogenic risks and on an assumption of risk activity (USEPA 2000). To calculate meal consumption limits based on a contaminant's carcinogenic effects, the first step is the calculation of daily consumption limits and is defined as (USEPA 2000)

$C R_{\text {lim,carcinogenic }}=\frac{A R L \cdot B W}{C S F_{\mathrm{corr}} \cdot C_{\mathrm{F}, \mathrm{m}}}$,

where $C R_{\text {lim }}$ is the maximum allowable tilapia consumption rate $\left(\mathrm{g}_{\text {day }}{ }^{-1}\right), B W$ is the consumer body weight $(\mathrm{kg}), A R L=10^{-5}$ is the maximum acceptable individual lifetime risk level suggested by USEPA (2000) (unit less), and $C S F_{\text {corr }}$ is a corrected cancer slope factor for the dose-response function $\left[\left(\mathrm{mg} \mathrm{kg}^{-1} \mathrm{day}^{-1}\right)^{-1}\right]$. The second step is the calculation of meal consumption limits and is defined as (USEPA 2000)

$C R_{\mathrm{mm}, \text { carcinogenic }}=\frac{C R_{\text {lim,carcinogenic }} \cdot T_{\mathrm{ap}}}{M S}$,

where $C R_{\mathrm{mm}}$ is the maximum allowable tilapia consumption rate (meals month ${ }^{-1}$ ), $M S$ is the meal size for human eating tilapia $\left(\mathrm{g} \mathrm{meal}^{-1}\right)$, and $T_{\mathrm{ap}}$ is the time averaging period (365.25 days 12 months $^{-1}=30.44$ days month $^{-1}$ (USEPA 2000)).

The data of amount of tilapia consumed by subsistence fishers in BFD-endemic area and residents in Taiwan were collected in 2004 and 2006, respectively. Data on tilapia consumption in subsistence fishers in BFD-endemic area in 2004 were adapted from Lin (Nanhua University, Chiayi, Taiwan, unpublished data), which was based on a questionnaire from 57 subsistence fishers. Data of tilapia consumption by residents in Taiwan was calculated from the reports of Fisheries Administration (2006) and Department of Statistics (2006). We divide the annual consumption quantities of tilapia by the number of residents (age $>5$ years) in Taiwan. These data were the newest among available literature. In order to provide an estimate for each of the model parameters, Monte Carlo (MC) analysis was performed to generate the probability distributions. The chi-square $\left(\chi^{2}\right)$ and KolmogorovSmirnov (K-S) goodness-of-fit were used to determine the optimal fitted distributions for MC simulation (Table 1). Data and distribution parameters were analyzed and 
estimated using the Statistica ${ }^{\circledR}$ software (Version 7.1, StatSoft, Tulsa, OK, USA). A sensitivity analysis was performed to identify and determine the most significant parameters influencing the value that presented in the uncertainty and variability analysis. The result shows that 10,000 iterations are sufficient to ensure the stability of results. We incorporate probability distributions into MC simulation to obtained $2.5 \%$ - and $97.5 \%$-tiles as $95 \%$ confidence interval (CI) for all uncertainty analyses. The Crystal Ball ${ }^{\circledR}$ software (Version 7.3, Decisioneering, Inc., Denver, Colorado, USA) was used to perform all the MC simulations.

\section{Results and Discussion}

Figure 1 depicts the exposure profile of the box and whisker plot and the exceedence risk functions with $95 \%$ CI with noncarcinogenic and carcinogenic effect based on different tilapia consumption rates. The comparison of 90\%-tile values shows that human exposure to As caused the relative skewness and spread in modeled output varied among specific organs. Our results demonstrate that the distribution of As concentration in human bladder is more highly skewed with a long tail at higher concentration (Fig. 1).

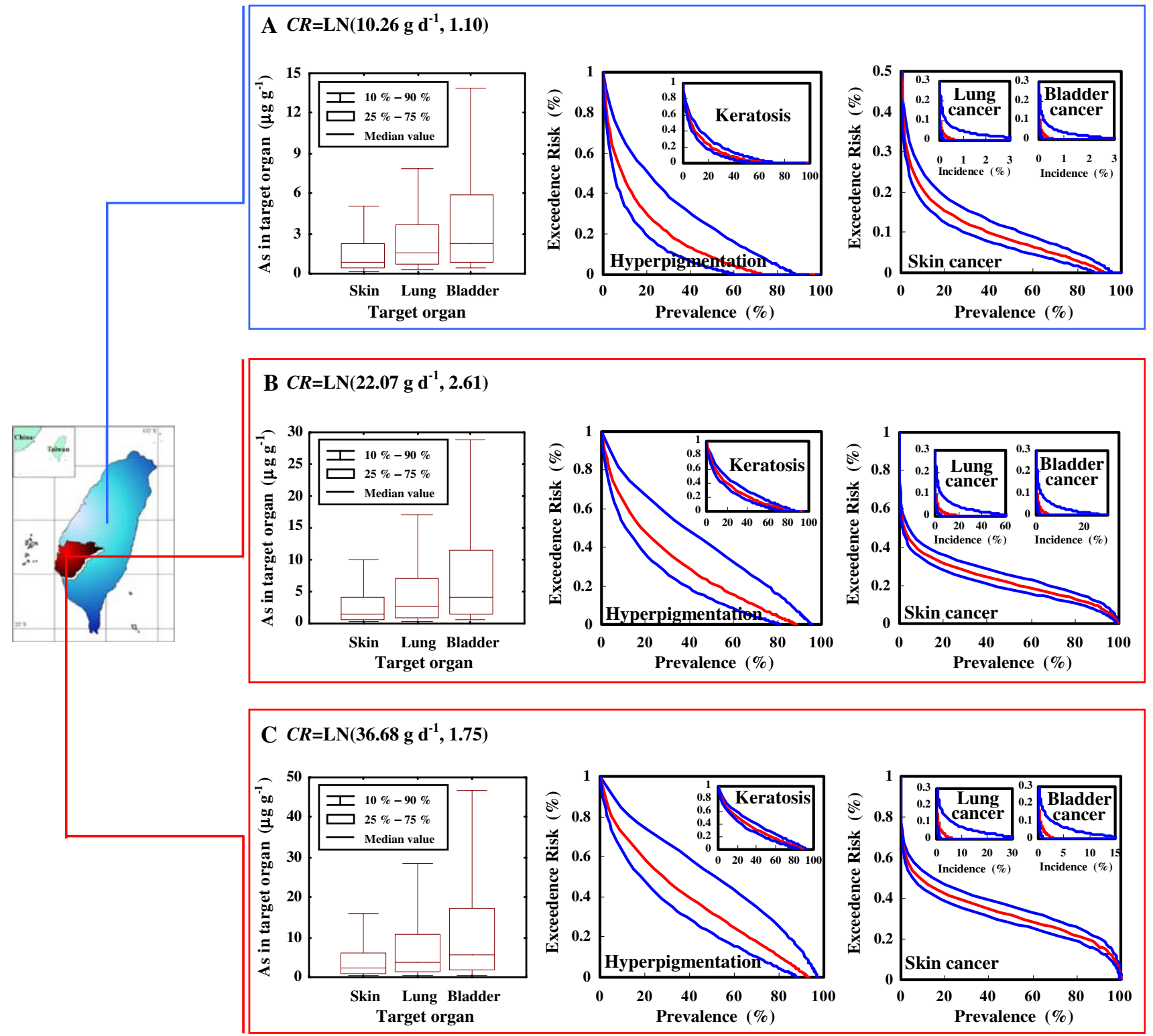

Fig. 1 Box and whisker plot representations of distributions of As concentration in human target organ and exceedence risk functions with $95 \% \mathrm{CI}$ in noncarcinogenic effects: hyperpigmentation, keratosis, and carcinogenic effects: skin cancer, lung cancer, and bladder cancer according to tilapia consumption rates (CR) of a residents in Taiwan and $\mathbf{b}, \mathbf{c}$ subsistence fishers in BFD-endemic area 
We optimal fitted the Hill model to published doseresponse functions to obtain the reconstructed dose-response profiles from Eq. 5 for arsenicosis and As-induced cancers. The Hill model and a 10,000 MC simulation provided an adequate fit for the data ( $\chi^{2}$ goodness-of-fit, $p>0.5$ ). The $n$ and $\mathrm{EC}_{50}$ values clearly show that there were significant differences in sensitivity to As in different human health effects. Regression analyses show that the nonlinear Hill three-parameter model in a good agreement with published dose-response models as judged by high $r^{2}$ values $(0.972-$ $0.999, p<0.05)$. The Hill coefficients $(n)$ for arsenicosis (1.344-1.402) and for As-induced cancers (3.206-3.474) are indicative of positive cooperativity.

Exceedence risk functions shown in Fig. 1 were based on the exposure and dose-response profiles for human consumption of farmed tilapia. Because of variability and uncertainty in model parameters from Eq. 6 describing the exceedence cdfs associated with a particular degree of prevalence and incidence, we applied the plotted probabilities calculated from the outcome of the MC simulation to estimate risks. For skin cancer from subsistence fishers $\left(C R=\mathrm{LN}\left(22.07 \mathrm{~g} \mathrm{day}^{-1}, 2.61\right)\right)$ in BFD-endemic area, the probabilities that $10 \%$ or more of human affected (risk $=0.10)$ is approximately $88 \%(95 \% \mathrm{CI}: 81 \%-93 \%)$. Therefore, the probability is 0.10 for at least $88 \%$ of human will be affected; whereas the probability is 0.5 for at least $2 \%(95 \%$ CI: $1 \%-4 \%)$ of human will pose health risks (Fig. 1b). Overall, risk diagrams (Fig. 1) demonstrate that consumption of farmed tilapia from BFD-endemic area may increase potential prevalence ratios of arsenicosis and skin cancer, yet pose no significant threat to health risks from lung and bladder cancers.

We recommended that the toxicological effect resulting in the more conservative consumption limits can be used to estimate an advisory since resulting limits would be protective of cancer health effects. Figure 2 shows the recommended consumption limit of tilapia from BFDendemic area in daily $\left(\mathrm{g} \mathrm{day}^{-1}\right)$ and meal (meals month ${ }^{-1}$ ) basis for adults in Taiwan, suggesting a median meal consumption rate for lung and bladder cancer effects of 5 to 17 meals month ${ }^{-1}$ (Fig. 2a) or 1.68 and $5.72 \mathrm{~g} \mathrm{day}^{-1}$, respectively (Fig. 2b). Our finding also indicates that the As-induced lung and bladder cancer risks generally considered a low individuals exposing risk in eating contaminated farmed tilapia of the people. This advice for human carcinogenicity health effects is more restrictive than consumption advice triggered contaminants in the tissues of farmed tilapia.

Sensitivity analysis indicates that the most important exposure variable for As in human organ-specific is As concentration in tilapia muscle. The contribution is approximately $54.1 \%$. Arsenic concentration in human organ is the key parameter for estimating human organspecific dose-response relationships. For allowable maximum consumption advice for As, the key parameter in the tilapia consumption limits is As concentration in tilapia muscle that contribution to variance is approximately $100 \%$.

In conclusion, this study indicates that consumption of As contaminated farmed tilapia may pose potential arsenicosis and skin cancer risks, yet pose low risks to human health risks from As-induced internal cancers. To precise determine the risk/benefit ratios from consumption of farmed tilapia are complicated, cautious interpretation of present data may substantially reduce the likelihood in dealing with uncertainty and risk management. This present probabilistic risk scheme provides general conclusions that are more robust than estimates made without probabilistic presentations of outcomes.
Fig. 2 Risk-based consumption advisories for human Asinduced lung and bladder cancer effects with maximum allowable tilapia consumption rates for a meal limits for consumption rate of tilapia $\left(C R_{\mathrm{mm}}\right)$, and $\mathbf{b}$ daily limits for consumption rate of tilapia $\left(C R_{\lim }\right)$

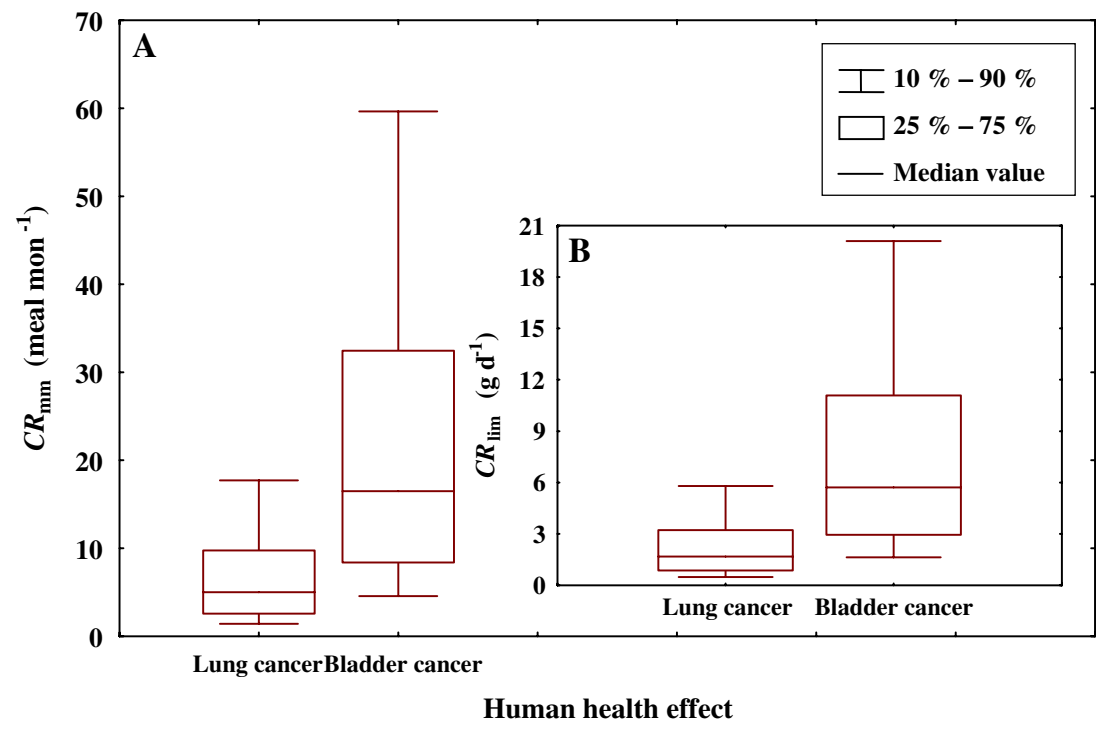


Acknowledgments This study was funded by the National Science Council of Republic of China (NSC 96-2313-B-039-001-MY2) and China Medical University (CMU 96-204).

\section{References}

Agency for Toxic Substances and Disease Registry (ATSDR) (2000) Toxicological profile for arsenic. US Department of Health and Human Services, Public Health Service, Atlanta, Georgia

Department of Health (2006) Health and national health insurance annual statistics information service. Department of Health, Ministry of Interior, Executive Yuan, Taipei, Taiwan, ROC (in Chinese)

Department of Statistics (2006) Yearly statistics of population. Department of Statistics, Ministry of Interior, Executive Yuan, Taipei, Taiwan, ROC (in Chinese)

Fisheries Administration (2006) Taiwan area: processed fishery products. Fisheries statistical year book. Fisheries Administration, Council of Agriculture, Executive Yuan, Taipei, Taiwan, ROC (in Chinese)

Huang YK, Lin KH, Chen HW, Chang CC, Liu CW, Yang MH, Hsueh YM (2003) Arsenic species contents at aquaculture farm and in farmed mouthbreeder (Oreochromis mossambicus) in blackfoot disease hyperendemic areas. Food Chem Toxicol 41:1491-1500. doi:10.1016/S0278-6915(03)00165-0

Lawrence GS, Gobas FAPC (1997) A pharmacokinetic analysis of interspecies extrapolation in dioxin risk assessment. Chemosphere 35:427-452. doi:10.1016/S0045-6535(97)00108-2

Leggett RW, Williams LR, Melo DR, Lipsztein JL (2003) A physiologically based biokinetic model for cesium in the human body. Sci Total Environ 317:235-255. doi:10.1016/S00489697(03)00333-4

Ling MP, Liao CM, Tsai JW (2005) A PBTK/TD modeling-based approach can assess arsenic bioaccumulation in farmed tilapia
Oreochromis mossambicus and human health risks. Integr Environ Assess Manage 1:40-45. doi:10.1897/IEAM_2004a004.1

Lung SCC, Chen CF, Hu SC, Bau YP (2003) Exposure of Taiwan residents to polychlorinated biphenyl congeners from farmed, ocean-caught, and imported fish. Environ Sci Technol 37:45794585. doi:10.1021/es026478f

Mann S, Droz PO, Vahter M (1996) A physiologically based pharmacokinetic model for arsenic exposure. II. Validation and application in humans. Toxicol Appl Pharmacol 140:471-486. doi:10.1006/taap.1996.0244

Tseng CH, Chong CK, Tseng CP, Centeno JA (2007) Blackfoot disease in Taiwan: its link with inorganic arsenic exposure from drinking water. Ambio 36:82-84. doi:10.1579/0044-7447(2007) 36[82:BDITIL]2.0.CO;2

US Environmental Protection Agency (USEPA) (1998) Guidelines for ecological risk assessment. EPA/630/R/95/002F. USEPA, Washington, DC

US Environmental Protection Agency (USEPA) (2000) Guidelines for assessing chemical contaminant data for use in fish advisories. II. Risk assessment and fish consumption limits. EPA/823/B/00/ 008. USEPA, Washington, DC

Yu D (1998) Uncertainties in a pharmacokinetic modeling for inorganic arsenic. J Environ Sci Health A33:1369-1390. doi:10.1080/10934529809376794

Yu D (1999a) A physiologically based pharmacokinetic model of inorganic arsenic. Regul Toxicol Pharmacol 29:128-141. doi:10.1006/rtph.1999.1282

Yu D (1999b) A physiologically modeling of inorganic arsenic: a short-term oral exposure model for humans. Chemosphere 39:2737-2747. doi:10.1016/S0045-6535(99)00207-6

Yu WH, Harvey CM, Harvey CF (2003) Arsenic in groundwater in Bangladesh: a geostatistical and epidemiological framework for evaluating health effects and potential remedies. Water Resour Res 39:1146. doi:10.1029/2002WR001327 